TITLE:

\title{
Mechanisms for the formation of monomers and oligomers during the pyrolysis of a softwood lignin
}

$\operatorname{AUTHOR}(S):$

Kotake, Takeo; Kawamoto, Haruo; Saka, Shiro

\section{CITATION:}

Kotake, Takeo ...[et al]. Mechanisms for the formation of monomers and oligomers during the pyrolysis of a softwood lignin. Journal of Analytical and Applied Pyrolysis 2014, 105: 309-316

ISSUE DATE:

2014-01

URL:

http://hdl.handle.net/2433/180646

RIGHT:

(c) 2013 Elsevier B.V.; This is not the published version. Please cite only the published version.; この論文は出版社版でありません。引用の際に は出版社版をご確認ご利用ください。 
$16 *$ Corresponding author: Tel/Fax: +81-75-753-4737

17 Email address: kawamoto@energy.kyoto-u.ac.jp

18 


\section{Abstract}

20 The formation of monomers and oligomers during the pyrolysis of softwood lignin has

21 been studied with particular emphasis on the reactivity of coniferyl alcohol (CA), which

22 is the anticipated product of the primary pyrolysis of lignin. Under the pyrolysis

23 conditions $\left(\mathrm{N}_{2} / 250-350^{\circ} \mathrm{C} / 5 \mathrm{~min}\right.$ ), the lignin contained in Japanese cedar (Cryptomeria

24 japonica) as well as the milled wood lignin (MWL) fraction gave the monomeric

25 guaiacols, including CA, coniferyl aldehyde, dihydroconiferyl alcohol, isoeugenol and 4-

26 vinylguaiacol. These products were similar to those obtained from the pyrolysis of CA,

27 although the yields were much lower. The addition of an aprotic solvent, such as

28 diphenoxybenzene (DPB), led to a substantial increase in the recovery of CA from its

29 pyrolysis reaction, likely by inhibiting the formation of the quinine methide intermediates

30 for the polymerization products, whereas the solvent effects were comparatively small

31 for the lignin pyrolysis. Alternatively, the inclusion of a H-donor $(1,2,3,10 \mathrm{~b}-$

32 tetrahydrofluoranthene) to the DPB led to a substantial increase in the yields of the

33 monomers and oligomers from lignin. Based on the present data, the pyrolytic formation

34 of the monomers and oligomers from the softwood lignin is discussed at the molecular 35 level.

\section{Keywords}

38 Lignin, Pyrolysis, Monomer, Oligomer, Molecular mechanism, Coniferyl alcohol. 


\section{Introduction}

40 Lignin, which represents about 20-30 wt \% of wood, is a potentially renewable

41 resource of aromatic chemicals, because lignin itself is an aromatic polymer composed of

42 phenylpropane-units linked through a variety of different ether (C-O) and condensed (C-

43 C) linkages. Processes for the conversion of lignin to the corresponding monomers are

44 invariably based on heat treatment, such as fast pyrolysis [1]. The pyrolysis of lignin has

45 been studied in the presence of hydrogenation catalysts [2, 3] as well as in the presence

46 of a hydrogen-donor solvent $[4,5]$ with the aim of improving the yield of the liquefied

47 products.

48 Given the polymeric nature of lignin, the depolymerization of the lignin chains and

49 subsequent secondary reactions are important steps in the production of low molecular

50 weight (MW) products. During the primary stages of the pyrolysis process, model

51 compound studies [6,7] have indicated that the ether linkages between the

52 phenylpropane-units are cleaved, effectively leading to the breakdown of the lignin

53 polymers, whereas the condensed (C-C) type linkages are comparatively stable and

54 remain largely intact. Model compound studies [6,7] have also suggested that cinnamyl

55 alcohol-type structures such as coniferyl alcohol and sinapyl alcohol represent the

56 primary structures that are formed through the pyrolytic cleavage of the $\beta$-ether linkages,

57 which represent the most abundant type of linkage in lignin. The yields of coniferyl

58 alcohol (CA) and sinapyl alcohol from the pyrolysis reactions of lignin and wood, 
59 however, have been reported to be less than those expected from the model compound

60 studies [8-13].

61 With the aim of identifying the root cause of this discrepancy, we have investigated

62 the reactivity of coniferyl alcohol at temperatures in the range of $200-350^{\circ} \mathrm{C}$ [14], which

63 covers the temperature range $\left(300-350^{\circ} \mathrm{C}\right)[15-17]$ where major weight-losses have been

64 reported to occur from lignin, using thermogravimetric analysis. Coniferyl alcohol tends

65 to condense to form polymerization products rather than undergoing an evaporation

66 process (recovery) or a side-chain conversion reaction, which could lead to the formation

67 of coniferyl aldehyde (an oxidation product), isoeugenol and dihydroconiferyl alcohol

68 (reduction products) or 4-vinylguaiacol bearing a C2 side chain [14]. Thus, differences in

69 the relative efficiencies of the evaporation/condensation/side-chain-conversion processes

70 have been proposed as factors determining the recovery of CA. The high level of

71 condensation reactivity arising from the effective formation of the quinone methide

72 intermediates, which were formed from the conjugated $\mathrm{C}=\mathrm{C}$ double bond on the $\mathrm{CA}$, has

73 been used as an explanation for the low recovery of CA. Based on these features of the

74 pyrolytic reactivity of CA, it has been suggested that coniferyl alcohol would suffer from

75 the occurrence of secondary reactions such as condensation and side-chain conversion

76 reactions prior to the recovery of $\mathrm{CA}$, even if it was formed from the primary pyrolysis

77 step of the guaiacyl (G)-type lignin.

78 With this in mind, we describe the pyrolysis behaviors of Japanese cedar wood

79 (Cryptomeria japonica) and the milled wood lignin (MWL) fraction. The formation 
80 behaviors of the monomeric guaiacols and oligomers have also been discussed at the

81 molecular level. The roles of aprotic solvent and H-donor in the lignin pyrolysis process

82 have also been discussed.

83

84

2. Experimental

\subsection{Materials}

trans-Coniferyl alcohol (trans-CA, 1) was prepared by the reduction of trans-coniferyl aldehyde with sodium borohydride. cis-Coniferyl alcohol (cis-CA, 2) was separated from

89 the pyrolysis mixture using preparative thin-layer chromatography (TLC) on a silica gel

90 plate (Kieselgel $60 \mathrm{~F}_{254}$, Merck). Dihydroconiferyl alcohol (4), isoeugenol (5), coniferyl

91 aldehyde (3), and 4-vinylguaiacol (6) were purchased from Nacalai Tesque Inc. (Kyoto,

92 Japan) as the guaranteed grades and used without further purification. Diphenoxybenzene

93 (DPB) and 1,2,3,10b-tetrahydrofluoranthene were purchased from Tokyo Chemical Co.,

94 Ltd. (Tokyo, Japan) as the guaranteed grades and used without further purification. The

95 chemical structures of all of the compounds prepared in this report were confirmed by

96 comparison of their ${ }^{1} \mathrm{H}-\mathrm{NMR}$ spectra with those of the authentic compounds. All of the

$97{ }^{1} \mathrm{H}-\mathrm{NMR}$ spectra were measured on a Varian AC-400 (400 MHz) spectrometer (Varian,

98 CA, USA). The chemical shifts and coupling constants $(J)$ are shown as $\delta$ and $\mathrm{Hz}$, 99 respectively. 
100 Japanese cedar wood flour ( $<80$ mesh), which had been pre-extracted with

101 ethanol/benzene $(2: 1, \mathrm{v} / \mathrm{v})$, and the MWL fraction isolated from cedar wood were used in

102 the current study. The characterization of these samples was described in our previous

103 report [18]. The MWL fraction contained some sugar component (3.0 wt $\%)$ from the

104 hemicellulose (hydrolysable sugar content by alditol-acetate method: glucose: $0.6 \mathrm{wt} \%$,

105 xylose: $0.7 \mathrm{wt} \%$, mannose: $0.3 \mathrm{wt} \%$, and arabinose: $0.2 \mathrm{wt} \%$ )

106

$107 \quad 2.2$ Pyrolysis

108 An open-top reactor system similar to that used in our previous report [19] was used

109 for the current work. trans-CA $(5.0 \mathrm{mg})$ was placed at the bottom of a Pyrex glass tube

110 with an internal diameter of $8.0 \mathrm{~mm}$, length of $300 \mathrm{~mm}$, and wall thickness of $1.0 \mathrm{~mm}$

111 through an evaporation process from a methanol (MeOH) solution. The wood or MWL

112 samples $(5.0 \mathrm{mg}$ each) were directly added to the bottom of the reactor. In some

113 experiments, DPB (50 mg) or a mixture of DPB (50 mg) and 1,2,3,10b-

114 tetrahydrofluoranthene (11.4 or $57 \mathrm{mg}$ ) was also added to the bottom of the reactor to

115 behave as an aprotic solvent or H-donor, respectively. The air inside the reactor was

116 purged with $\mathrm{N}_{2}$ using an aspirator connected to the reactor through a three-way tap. The

117 bottom two thirds of the reactor were then placed into a muffle furnace, which had been

118 preheated to a temperature in the range of $250-350^{\circ} \mathrm{C}$, through a small hole in the top of

119 the furnace. Following a period of heating for $5 \mathrm{~min}$, the reactor was immediately cooled 
120 by flowing air over the reactor for 1 min before being cooled further with cold water for $1211 \mathrm{~min}$.

122 Following the pyrolysis process, the inside of the reactor was rinsed with $\mathrm{MeOH}(1.0$

$123 \mathrm{~mL}$ ) to recover the $\mathrm{MeOH}$-soluble products and the remaining $\mathrm{CA}$ (in the case of the 124 pyrolysis of $\mathrm{CA}$ ). The $\mathrm{MeOH}$-soluble portions were then subjected to the following 125 analytic procedures.

\subsection{Product analysis and quantification}

128 The process used for the identification of the products 1-6 has been described in our

129 previous paper [14]. The quantification of these products was mainly conducted by

130 analyzing the $\mathrm{MeOH}$-soluble portions by high-performance liquid chromatography 131 (HPLC) on a Shimadzu LC-10A system (Shimadzu, Kyoto, Japan) using a Cadenza CD

132 C-18 column with a flow rate of $0.7 \mathrm{~mL} / \mathrm{min}$ at temperature of $40^{\circ} \mathrm{C}$. A binary solvent 133 system composed of $\mathrm{MeOH}$ and $\mathrm{H}_{2} \mathrm{O}$ was used for the HPLC analysis with a gradient of $13430 / 70(0 \mathrm{~min}) \rightarrow 45 / 55(0 \mathrm{~min} \rightarrow 5 \mathrm{~min}), 45 / 55(5 \mathrm{~min} \rightarrow 25 \mathrm{~min}) \rightarrow 100 / 0(25 \mathrm{~min} \rightarrow$ $13555 \mathrm{~min}$ ), and 100/0 (55 $\mathrm{min} \rightarrow 70 \mathrm{~min})$. The HPLC system was equipped with a UV 136 detector operating at a wavelength of $280 \mathrm{~nm}$. The product yields and recoveries of CA 137 (in the case of the CA pyrolysis) were determined from a comparison of their peak areas 138 with that of 1,2,3-trimethoxybenzene, which was used as an internal standard. For the 139 dihydroconiferyl alcohol, the UV absorption at $280 \mathrm{~nm}$ was relatively low, which could 140 potentially lead to a reduction in the accuracy of the quantification provided by the HPLC 
141 analysis. With this in mind, the yield of dihydroconiferyl alcohol was also determined on

142 the basis of the peak area of one of its ${ }^{1} \mathrm{H}-\mathrm{NMR}$ signals $\left(\delta 2.65 \mathrm{ppm}, \mathrm{t}, J=7.4, \mathrm{C}_{\alpha}-\underline{\mathrm{H}}\right)$.

143 Gel-permeation chromatography (GPC) was used to obtain molecular weight (MW)

144 distribution information for the $\mathrm{MeOH}$-soluble products using the Shimadzu LC-10A 145 system with a Shodex KF-801 column at a flow rate of $0.6 \mathrm{~mL} / \mathrm{min}$ and a temperature of

$14640^{\circ} \mathrm{C}$. THF was used as an eluent with UV detection at a wavelength of $280 \mathrm{~nm}$.

147 All pyrolysis experiments were repeated at least twice, and the product yields were not

148 very different in these sets of experiments, although the data presented in this paper were 149 not treated statistically.

1512.4 Bond dissociation energy calculation

152 A density functional theory (DFT) calculation was conducted under AM1 at the 153 B3LYP/6-311+G** level with "Spartan'08" (Wavefunction Inc., CA, USA) to obtain a 154 bond dissociation energy (BDE). A zero-point energy correction was not made in the 155 current study.

\section{Results and discussion}

The Japanese cedar wood and the MWL fraction were pyrolyzed under $\mathrm{N}_{2}$ at

160 temperatures in the range of $250-350^{\circ} \mathrm{C}$ for $5 \mathrm{~min}$, and the resulting pyrolyzates obtained

161 as the $\mathrm{MeOH}$-soluble portions were analyzed by HPLC. The chromatograms $\left(350^{\circ} \mathrm{C}\right)$ are 
162 illustrated in Fig. 1 together with a chromatogram from the pyrolysis of CA conducted

163 under similar conditions. From the chromatograms, it was possible to identify trans-CA

164 (1), cis-CA (2), coniferyl aldehyde (3), dihydroconiferyl alcohol (4), isoeugenol

165 (trans/cis, 5) and 4-vinylguaiacol (6). In our previous paper, we reported that all of these

166 materials were formed from the pyrolysis of CA [14]. The shapes of the chromatograms

167 were quite similar except for the signals with retention times less than 10 min from the

168 wood sample. These signals may be attributed to the wood polysaccharides, such as

169 cellulose and hemicellulose. The intensities of these signals in the chromatograms from

170 the MWL and the wood samples, however, were much lower than those observed in the

171 chromatogram from CA. These observations suggested that the pyrolysis reactions of the

172 MWL and the wood samples gave the monomeric guaiacols 1-6 in much lower yields

173 than those observed in the pyrolysis of CA. The combined yields of the monomers 1-6

174 were only 2.1 and $2.7 \mathrm{wt} \%$ (lignin-basis) at $350^{\circ} \mathrm{C}$ for the MWL and wood samples,

175 respectively. Unfortunately, these yields were too low to enable a discussion of the role

176 of CA formation during the pyrolysis of the G-type lignin.

177 CA is known to polymerize to form polymerization products as opposed to 178 undergoing the evaporation process [14,20,21] or conversion to the side-chain179 conversion products mentioned above [14,20]. Conducting the pyrolysis in a solvent 180 would allow for this polymerization reaction to be effectively suppressed. To increase the 181 yields of the monomeric guaiacols from the wood and MWL samples, the pyrolysis was 182 also conducted in diphenoxybenzene (DPB), which is an aprotic solvent. Pyrolysis 
183 conditions including 1,2,3,10b-tetrahydrofluoranthene, which is a $\mathrm{H}$-donor, were also

184 used to develop a better understanding of the influence of the H-donor on the formation

185 of the monomers, because radical mechanisms have been suggested for the side-chain

186 conversions of CA during the pyrolysis. Prior to a discussion of the pyrolysis reactions of

187 the MWL/wood samples, the influences of the solvent and the H-donor on the pyrolysis

188 of CA were also studied. The recoveries of CA, as well as the yields of the monomeric

189 guaiacols 2-6, from the pyrolysis reactions of CA conducted under neat, solvent and

190 solvent/H-donor conditions are summarized in Fig. 2. The yields of the monomeric

191 guaiacols 1-6 from the pyrolysis of the wood and MWL samples under three different

192 pyrolysis conditions are also summarized in Fig. 3.

193 For the pyrolysis of CA, the use of the solvent led to an increase in the recovery of

194 CA at all of the temperatures tested in the current study (Fig. 2). The recoveries increased 195 from 14.3 to $40.5 \%$ (neat conditions) to 57.6 to $82.0 \%$ (in DPB). The values reached 70.8

196 to $83.7 \mathrm{wt} \%$ when the yields of the monomeric guaiacols 2-6 were also included. As

197 illustrated in Fig. 4A, it has been suggested that the quinone methides are important 198 intermediates in the polymerization reactions [14]. The proton-transfer represents an 199 essential step for these reactions because the quinone methide intermediates are formed 200 through heterolysis-type reactions. Under the neat conditions, the intermolecular proton201 transfer would only occur in the CA melt. In contrast, however, the occurrence of a 202 proton-transfer step of this type would be ineffective under the solvation conditions in 
203 DPE, as illustrated in Fig. 4A and this would suppress the polymerization reactivity of 204 CA.

205 The addition of the H-donor to the solution of CA in DPE led to a significant change

206 in the composition of the monomeric guaiacols resulting from the pyrolysis of CA, with

207 the conversion of CA to dihydroconiferyl alcohol (4) and isoeugenol (5) being enhanced 208 by the presence of the H-donor. This enhancement in the conversion process can be 209 explained in terms of the action of the hydrogen radical, as illustrated in Fig. 4B. The 210 thermal decomposition of 1,2,3,10b-tetrahydrofluoranthene would give rise to the 211 hydrogen radical through the abstraction of the benzyl hydrogen, followed by a $\beta$ 212 scission reaction. The resulting hydrogen radical could then add to the $\mathrm{C}=\mathrm{C}$ double bond 213 of CA to form compounds $\mathbf{4}$ and $\mathbf{5}$, as discussed in our previous paper [14]. Alternatively, 214 these formation mechanisms suggest that the reactions leading to the formation of 215 dihydroconiferyl alcohol (4) and isoeugenol (5) could be used as probes to provide 216 information about the relative concentration of the hydrogen radical in the pyrolysis 217 environment. This idea will be discussed in greater detail below.

218 The solvent and the H-donor affected the pyrolysis reactions of the wood and MWL 219 samples in different ways (Fig. 3). The use of the solvent increased the yields of the 220 monomeric guaiacols 1-6 as observed in the pyrolysis of CA, and the H-donor was also 221 very effective for increasing the yields of the monomeric guaiacols. The yields of the 222 monomeric guaiacols 1-6 at a temperature of $350^{\circ} \mathrm{C}$ increased from 2.1 and 2.7 (neat) $\rightarrow$ 2233.9 and 4.3 (in DPE) $\rightarrow 8.3$ and $12.8 \mathrm{wt} \%$ (in DPE/H-donor) for the MWL and the wood 
224 samples, respectively. Even the yield of CA tended to increase in the presence of the H225 donor, although the recovery of CA during the pyrolysis of CA was reduced significantly 226 as a consequence of side-chain conversion reactions. The discrepancy between the CA 227 and MWL/wood samples can be explained in terms of the characteristic features of the 228 lignin pyrolysis, with model studies reporting that the cleavage of the lignin ether 229 linkages occurs predominantly according to homolytic cleavage mechanisms [22,23]. 230 Accordingly, the pyrolytic cleavage of the lignin ether linkages would release large 231 quantities of radical species, which would tend to form the corresponding radical 232 coupling products even in the aprotic solvent, DPE. It would therefore be necessary to 233 stabilize these radicals through hydrogen donation to provide the monomeric guaiacols.

234 As observed in the pyrolysis of CA, the yields of dihydroconiferyl alcohol (4) and 235 isoeugenol (5) increased in the presence of the H-donor, likely because of the occurrence 236 of similar mechanisms, as shown in Fig. 4B.

237 As for the composition of the monomeric guaiacols following the pyrolysis reactions 238 of MWL and wood, at a relatively low pyrolysis temperature of $250^{\circ} \mathrm{C}$, the major 239 monomeric guaiacol was found to be coniferyl aldehyde (3) [67 (MWL) and 80\% (wood), 240 monomer-basis], as opposed to CA [33 (MWL) and 12\% (wood), monomer-basis].

241 Similar results have also been reported by Arias et al. [13] who studied the pyrolysis242 GC/MS analysis of pine wood at various temperatures. Increases in the pyrolysis 243 temperature from $250^{\circ} \mathrm{C}$ to 300 and $350^{\circ} \mathrm{C}$ led to increases in the amounts of 244 dihydroconiferyl alcohol (4), isoeugenol (5) and 4-vinylguaiacol (6) (Fig. 3). 
245 The preferential formation of coniferyl aldehyde at relatively low temperatures can

246 be understood in terms of the relative amount of radical/H-donor (or $\mathrm{H}$ radical), as

247 discussed in Fig. 5. During the primary pyrolysis of the lignin, the pyrolysis environment

248 is considered to be under radical conditions because of the formation of large quantities

249 of radicals through the homolytic cleavage of the lignin ether linkages. Under such $\mathrm{H}$ -

250 donor-deficient conditions, these radical species would tend to form the corresponding

251 radical coupling products or be stabilized by abstracting hydrogens from other molecules.

252 The $\mathrm{C}_{\gamma}$-hydrogen of $\mathrm{CA}$, which is at the conjugated allyl position, may act as a $\mathrm{H}$-donor

253 to these radicals, and this could result in the formation of coniferyl aldehyde via the

254 release of a hydrogen radical. The resulting hydrogen radical could in turn be used for the

255 stabilization of the radical species, rather than undergoing addition to the side-chain $\mathrm{C}=\mathrm{C}$

256 double bonds.

257 At a higher pyrolysis temperature of $350^{\circ} \mathrm{C}$, the pyrolysis environment would change

258 to become richer in $\mathrm{H}$-donor species ( $\mathrm{H}$ radical). Asmadi et al. [24] have suggested that

259 the hydrogen radicals formed during charring reactions effectively promoted the

260 pyrolytic radical chain reactions of guaiacol and syringol, which were used as model

261 aromatic nuclei of lignin. The charring reaction itself represents a form of

262 polyaromatization. It is generally believed that this process releases hydrogen radicals via

263 similar $H$-abstraction/ $\beta$-scission reactions to those discussed for the thermal

264 decomposition of 1,2,3,10b-tetrahydrofluoranthene in Fig. 4B. The presence of enhanced

265 levels of $\mathrm{H}$-donor (H-radical) species would provide an effective explanation of the 
266 increasing yields of dihydroconiferyl alcohol (4) and isoeugenol (5) observed at the

267 higher pyrolysis temperatures.

268 A comparison of the results for CA with those from MWL/wood revealed that the

269 MWL/wood tended to produce more 4-vinylguaiacol (6) (Figs. 2 and 3). This may be

270 attributed to the elimination of $\mathrm{C}_{\gamma}$ occurring before cleavage of the $\beta$-ether linkages [6].

271 The resulting vinyl ether structure would form 4-vinylguaiacol.

272 The lower yields of CA from the pyrolysis reactions of the MWL and wood samples

273 than those expected from the pyrolysis of CA and the model compound study would be

274 attributed to the "polymer effect". The cleavage of the ether linkages at the terminal 275 groups of the lignin macromolecule would lead to the direct formation of monomer units.

276 This would represent a case very similar to those of the pyrolysis reactions of CA and

277 other model compounds. In contrast, the cleavage of the ether linkages within the 278 polymer would not lead to the immediate formation of monomer units from lignin 279 because of its polymeric nature, and would instead give rise to truncated polymeric units. 280 In these circumstances, the pyrolyzates would remain in the heating zone and undergo 281 secondary pyrolysis reactions, such as radical coupling and side-chain conversion 282 reactions, prior to the formation of monomer units through the cleavage of their ether 283 linkages, because the initial ether cleavage reactions would produce more labile 284 structures containing $\mathrm{C}=\mathrm{C}$ side-chains and radicals. These "polymer effects" would lead 285 to a reduction in the yield of the monomer and an increase in the concentration of the 286 side-chain conversion products, including compounds 2-6. 
On the basis of a report suggesting that the condensed (C-C) linkages in the lignin macromolecule, which comprise $30-40 \%$ of the linkages between the phenylpropane-

289 units in lignin, are stable during the primary pyrolysis of lignin [6,7], we believe that 290 these linkages would remain intact during pyrolysis under the present conditions. This 291 would therefore suggest that the primary pyrolysis of lignin leads to the formation of 292 oligomeric products together with the monomers. The yields of the monomer and 293 oligomer units were estimated on the basis of a schematic softwood lignin structure from 294 the literature composed of 16 phenylpropane-units [25]. The estimated yields were 295 determined under the assumption that all of the ether linkages are cleaved and any further 296 secondary reactions do not occur during pyrolysis (Fig. 6). The estimated yields were 297 found to be 31 (monomer) and 69\% (oligomer). These results therefore suggested that the 298 oligomeric products must be produced in much higher yields than the monomeric 299 products. These features also provided an explanation for the comparatively low yields of 300 the monomers from MWL/wood.

301 Fig. 7 shows the chromatograms obtained from the GPC analyses of the MeOH302 soluble portions from the pyrolysis reactions of the MWL and the wood samples. 303 Although the signals observed in the higher MW region (i.e., shorter retention times) than 304 that of CA were very small under the neat conditions, these signals increased 305 significantly when the pyrolysis process was conducted in DPE, and increased even more 306 so when the process was conducted in the presence of the H-donor. These results 307 indicated that the primary oligomeric products with lower volatilities could polymerize to 
308 form insoluble products rather than evaporate, as they would under the neat conditions.

309 This polymerization reaction was effectively suppressed in DPF and in the presence of

310 the H-donor, for reasons similar to those described for the formation of the monomeric

311 products.

312 All of the results observed in the current paper can be adequately explained by the

313 formation of $\mathrm{CA}$ and the subsequent secondary reactions of the CA radical as a major

314 pathway for the pyrolysis of the G-type lignin. The stabilization of the primary radical

315 products with a H-donor in an aprotic solvent was also identified as being important for

316 two reasons, because (1) it led to an increase in the yields of the monomers and

317 oligomers; and (2) it inhibited the condensation reaction by suppressing the formation of

318 the quinone methide intermediates. Conducting the pyrolysis in an aprotic solvent in the

319 presence of a $\mathrm{H}$-donor could therefore come to represent an effective method for the

320 pyrolysis of lignin (Fig. 8). Dihydroconiferyl alcohol and isoeugenol would be formed as

321 the major monomeric products under these conditions. The yields of the monomers [8.3

322 and 12.8 wt\% from the MWL and the wood samples, respectively (DPE/H-

323 donor $\left.\left./ 350^{\circ} \mathrm{C}\right)\right]$ were not small in comparison with the theoretical monomer yields

324 described above.

\section{Conclusions}


329 Pyrolysis of coniferyl alcohol:

330 (1) Conducting the pyrolysis in DPB, which is an aprotic solvent, effectively inhibited

331 the polymerization of CA. This is probably through the inhibition of the proton332 transfer, which is as an important step required for the formation of the quinone 333 methide intermediates (a heterolysis reaction).

334 (2) The addition of the H-donor (1,2,3,10b-tetrahydrofluoranthene) led to an increase in 335 the yields of the side-chain reduction products (i.e., dihydroconiferyl alcohol and 336 isoeugenol) via the addition of a hydrogen radical (from the H-donor thermal 337 decomposition) to the $\mathrm{C}=\mathrm{C}$ double bond of the side-chain in $\mathrm{CA}$.

339 Pyrolysis of Japanese cedar (guaiacyl-type) lignin:

340 (1) The MWL and the wood samples gave coniferyl aldehyde, dihydroconiferyl alcohol, 341 isoeugenol and 4-vinylguaiacol as the monomeric guaiacols, together with CA. These 342 products were similar to those obtained from the pyrolysis of CA. These results 343 indicated that the CA pathway exists during the pyrolytic formation of the monomers 344 from lignin.

345 (2) Unlike for CA, both DPB and H-donor were required for effective formation of 346 monomer from MWL/wood. This can be explained by the stabilization of the CA 347 radical with the $\mathrm{H}$-donor, as a primary product from the pyrolytic cleavage of the 348 ether linkages in lignin. Dihydroconiferyl alcohol and isoeugenol were the major 349 monomers under these conditions. 
350 (3) At the lower pyrolysis temperature of $250^{\circ} \mathrm{C}$, coniferyl aldehyde was the major 351 monomeric product from lignin, instead of CA. This can be explained with the H352 donor/radical balance. More radical environment at such lower temperature would 353 lead to oxidation of the $\mathrm{C}_{\gamma}$ in $\mathrm{CA}$ through abstraction of the $\mathrm{C}_{\gamma}$ - $\mathrm{H}$ by radical species.

354 (4) The oligomeric products should also be focused as the initial products along with the 355 monomers, because the condensed (C-C) linkages would be stable during the primary 356 pyrolysis of lignin. The oligomeric products with relatively low volatilities 357 preferentially condensed under the neat conditions. The use of DPB and H-donor 358 significantly increased the yields of oligomers through stabilization against this 359 condensation.

360 (5) "Polymer effect" was suggested as a mechanism for promoting the secondary 361 reactions of the lignin primary pyrolyzates.

\section{Acknowledgments}

365 This work was supported by a Grant-in-Aid for Scientific Research (B)(2) (Grant no. 366 24380095, 2012.4-2016.3) and the Kyoto University Global COE program for "Energy 367 Science in the Age of Global Warming". 


\section{References}

[1] M. P. Pandey, C. S. Kim, Lignin depolymerization and conversion: A review of thermochemical methods, Chem. Eng. Technol. 34 (2011) 29-41.

[2] D. Meier, J. Berns, C. Grümwald, O. Faix, Analytical pyrolysis and semicontinuous catalytic hydropyrolysis of organocell lignin, J. Anal. Appl. Pyrolysis 25 (1993) 335-347.

[3] A. Oasmaa, A Jphansson, Catalytic hydrotreating of lignin with water-soluble molybdenum catalyst, Energ Fuels 7 (1993) 426-429.

[4] R. W. Thring, J. Breau, Hydrocracking of solvolysis lignin in a batch reactor, Fuel 75 (1996) 795-800.

[5] M. Kleinert, T. Barth, Phenols from lignin, Chem. Eng. Technol. 31 (2008) 736745.

[6] H. Kawamoto, S. Horigoshi, S. Saka, Pyrolysis reactions of various lignin model dimers, J.Wood.Sci. 53 (2007) 168-174.

[7] T. Nakamura, H. Kawamoto, S. Saka, Pyrolysis behavior of Japanese cedar wood lignin studied with various model dimers, J. Anal. Appl. Pyrolysis 81 (2008) 173182.

[8] R.J. Evans, T. A. Milne, Molecular characterization of the pyrolysis of biomass. 1. Fundamentals, Energy Fuels, 1 (1987) 123-137. 
[9] W. Genuit, J. J. Boon, O. Faix, Characterization of beech milled wood lignin by pyrolysis-gas chromatography-photoionization mass spectrometry, Anal.Chem. 59 (1987) 508-513.

[10] J. Ralph, R. D. Hatfield, Pyrolysis-GC-MS characterization of forage materials, J. Agric. Food Chem. 39 (1991) 1426-1437.

[11] K. Sipilä, E. Kuoppala, L. Fagernäs, A. Oasmaa, Characterization of biomassbased flash pyrolysis oils, Biomass Bioenergy 14 (1998) 103-113.

[12] B. Scholze, D. Meier, Characterization of the water-insoluble fraction from pyrolysis oil (pyrolytic lignin). Part I. PY-GC-MS, FTIR, and functional groups, J. Anal. Appl. Pyrolysis 60 (2001) 41-54.

[13] M.E. Arias, O. Polvillo, J. Rodríguez, M. Hernández, J.A. González-Pérez, F.J. González-Vila, Thermal transformations of pine wood components under pyrolysis/gas chromatography/mass spectrometry conditions, J. Anal. Appl. Pyrolysis 77 (2006) 63-67.

[14] T. Kotake, H. Kawamoto, S. Saka, Pyrolysis reactions of coniferyl alcohol as a model of the primary structure formed during lignin pyrolysis, J. Anal. Appl. Pyrolysis 104 (2013) 573-584.

[15] O. Faix, E. Jakab, F. Till, T. Székely, Study on low mass thermal-degradation products of milled wood lignins by thermogravimetry-mass-spectrometry, Wood Sci. Technol. 22 (1988) 323-334. 
[16] D.J. Gardner, T.P. Schultz, G.D. McGinnis, The pyrolytic behavior of selected lignin preparations, J. Wood Chem. Technol. 5 (1985) 85-110.

[17] E. Jakab, O. Faix, F. Till, Thermal decomposition of milled wood lignins studied by thermogravimetry/mass spectrometry, J. Anal. Appl. Pyrolysis 40-41 (1997) 171-186.

[18] T. Hosoya, H. Kawamoto, S. Saka, Pyrolysis behavior of wood and its constituent polymers at gasification temperature, J. Anal. Appl. Pyrolysis 78 (2007) 328-336.

[19] N. Shimada, H. Kawamoto, S. Saka, Different action of alkali/alkaline earth metal chlorides on cellulose pyrolysis, J. Anal. Appl. Pyrolysis 81 (2008) 80-87.

[20] C. P. Masuku, Thermolytic decomposition of coniferyl alcohol, J. Anal. Appl. Pyrolysis 23 (1992) 195-208.

[21] T. Nakamura, H. Kawamoto, S. Saka, Condensation reactions of some lignin related compounds at relatively low pyrolysis temperature, J. Wood Chem. Technol. 27 (2007) 121-133.

[22] H. Kawamoto, T. Nakamura, S. Saka, Pyrolytic cleavage mechanisms of ligninether linkages: A study on $p$-substituted dimers and trimers, Holzforschung 62 (2008) 50-56.

[23] H. Kawamoto, M. Ryoritani, S. Saka, Different pyrolytic cleavage mechanisms of $\beta$-ether bond depending on the side-chain structure of lignin dimers, J. Anal. Appl. Pyrolysis 81 (2008) 88-94. 
[24] M. Asmadi, H. Kawamoto, S. Saka, The effect of combining guaiacol and syringol on their pyrolysis, Holzforschung 66 (2012) 323-330.

[25] E. Adler, Lignin chemistry-past, present and future, Wood Sci. Technol. 11 (1977) 169-218. 


\section{Figure Legends}

Fig. 1 HPLC chromatograms of the methanol-soluble portions obtained by the pyrolysis of coniferyl alcohol (CA), Japanese cedar MWL and wood, with identification of some signals $\left(\mathrm{N}_{2} / 350^{\circ} \mathrm{C} / 5 \mathrm{~min}\right)$.

IS (internal standard) : 1,2,3-trimethoxybenzene

Fig. 2 Influence of the addition of the aprotic solvent (diphenoxybenzene, DPB) and the $\mathrm{H}$-donor $(1,2,3,10 \mathrm{~b}$-tetrahydrofluoranthene) on the recovery of coniferyl alcohol and the yields of other monomeric guaiacols from the pyrolysis of coniferyl alcohol (CA) (CA $5.0 \mathrm{mg} / \mathrm{N}_{2} / 250-350^{\circ} \mathrm{C} / 5 \mathrm{~min}$ ).

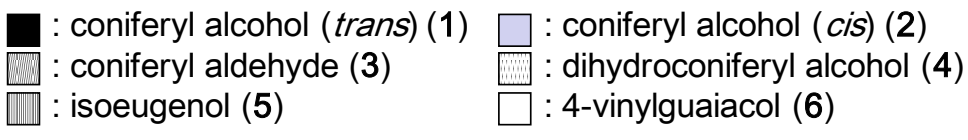

Fig. 3 Influence of the addition of the aprotic solvent (diphenoxybenzene, DPB) and the $\mathrm{H}$-donor $(1,2,3,10 \mathrm{~b}$-tetrahydrofluoranthene) on the yields of monomeric guaiacols from the pyrolysis of Japanese cedar MWL and wood (MWL or wood $\left.5.0 \mathrm{mg} / \mathrm{N}_{2} / 250-350^{\circ} \mathrm{C} / 5 \mathrm{~min}\right)$.

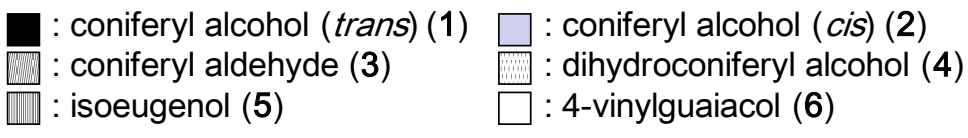

Fig. 4 A proposed suppression mechanism of the aprotic solvent for the thermal polymerization of coniferyl alcohol (CA) (A) and a proposed role of the H-donor $(1,2,3,10 \mathrm{~b}$-tetrahydrofluoranthene) as a source of the hydrogen radical for reduction of the side-chain double bond of CA (B).

Fig. 5 A proposed role of the $\mathrm{H}$-donor and $\mathrm{H}$-radical for the formation of the monomeric guaiacols during the pyrolysis of Japanese cedar lignin.

Fig. 6 Estimated yields of the monomeric and oligomeric units from a schematic softwood lignin structure comprising 16 C9 units [25], by assuming that all the ether linkages between aromatic ring and side-chain are cleaved without any further secondary decomposition.

Fig. 7 Influence of the addition of the aprotic solvent (1,3-diphenoxybenzene, DPB) and the $\mathrm{H}$-donor $(1,2,3,10 \mathrm{~b}$-tetrahydrofluoranthene $)$ on the formation behaviors of the oligomeric products, as shown in the gel permeation chromatograms of the methanol-soluble portions obtained from the pyrolysis of Japanese cedar MWL or wood (MWL or wood $5.0 \mathrm{mg} / \mathrm{N}_{2} / 250-350^{\circ} \mathrm{C} / 5 \mathrm{~min}$ ).

a: retention time of coniferyl alcohol 
$---: 250^{\circ} \mathrm{C} \quad---: 300^{\circ} \mathrm{C} \quad-: 350^{\circ} \mathrm{C}-: 350^{\circ} \mathrm{C}$ (+ H-donor)

*: H-donor : 1,2,3,10b-tetrahydrofluoranthene (11.4 mg/ $5.0 \mathrm{mg}$ of MWL or wood)

Fig. 8 Conducting the pyrolysis in aprotic solvent in the presence of H-donor as an effective way to convert softwood lignin to dihydroconiferyl alcohol, isoeugenol and oligomers. 


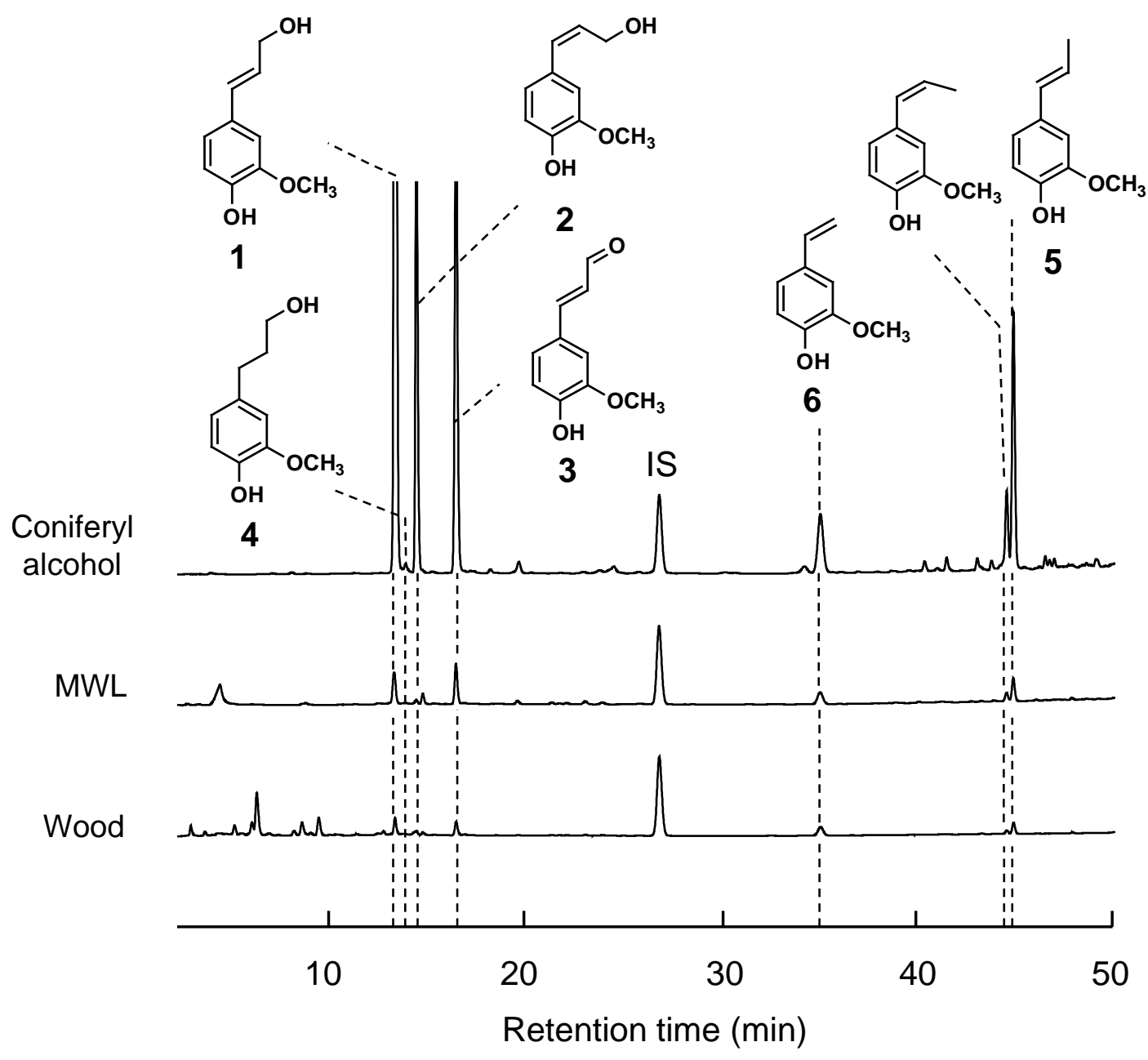

Fig. 1 


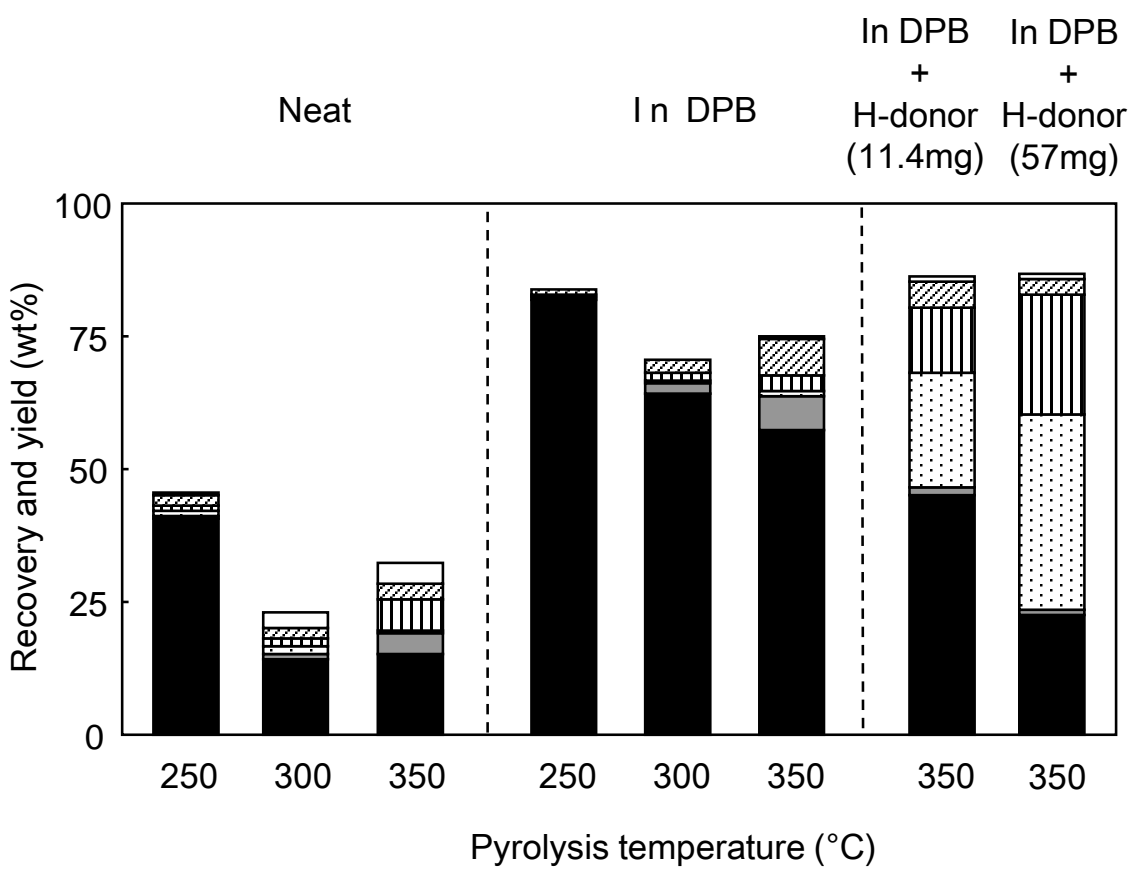

Fig. 2 


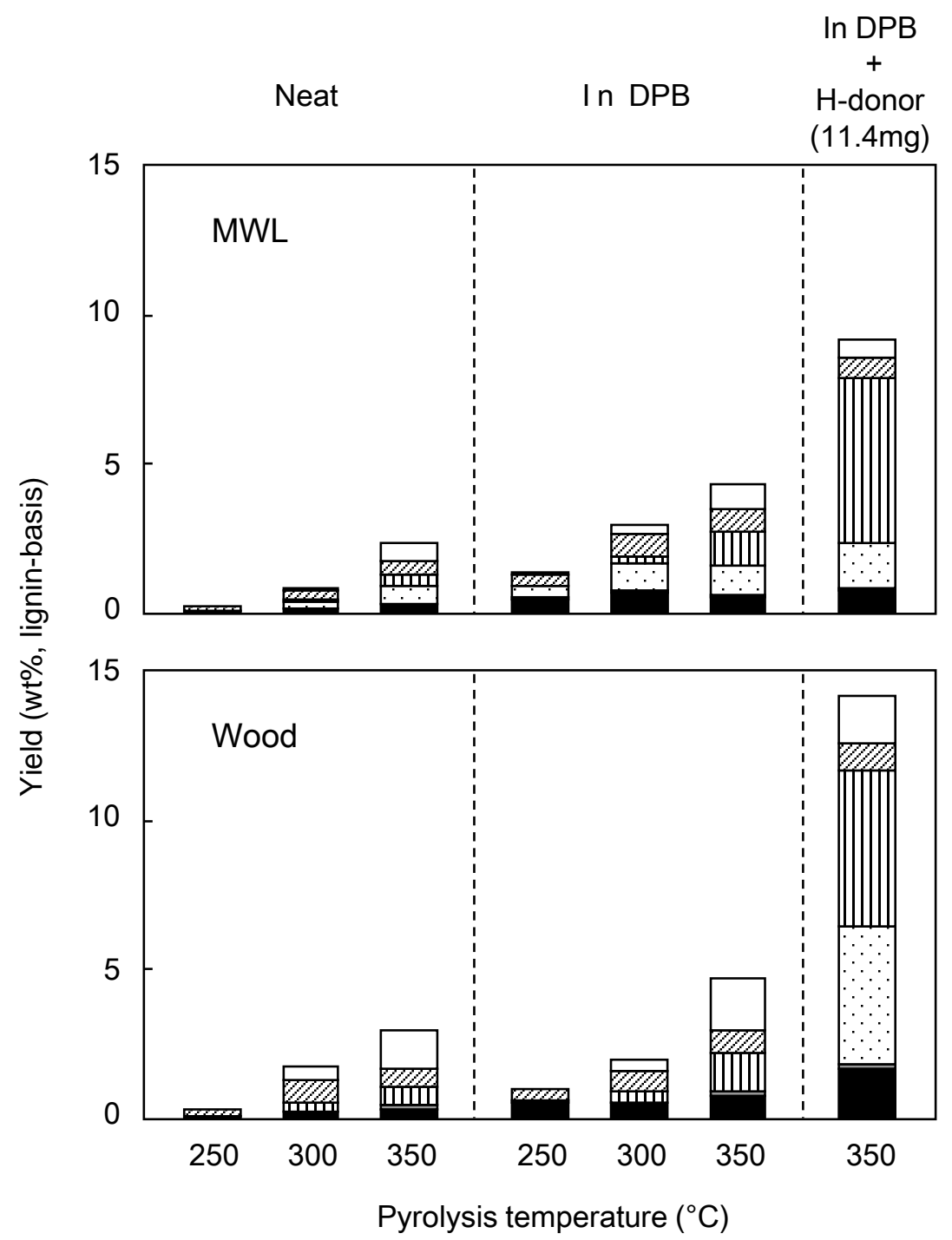

Fig. 3 


\section{A: Role of DPB}

Neat condition

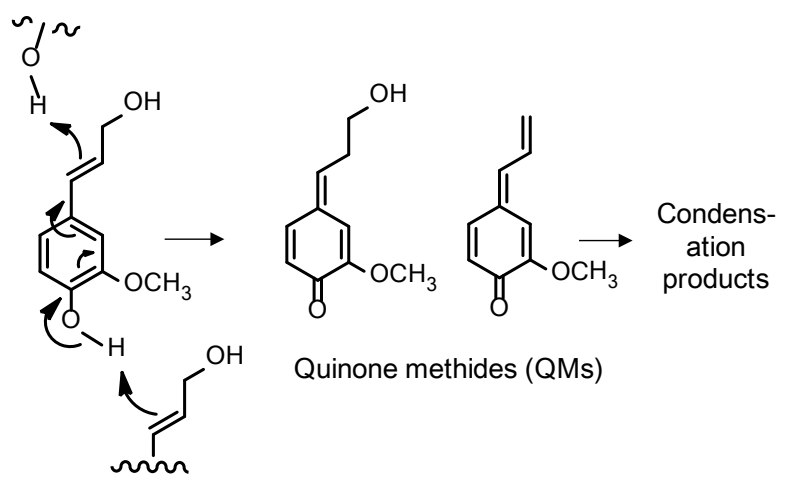

$\underline{\ln \mathrm{DPB}}$

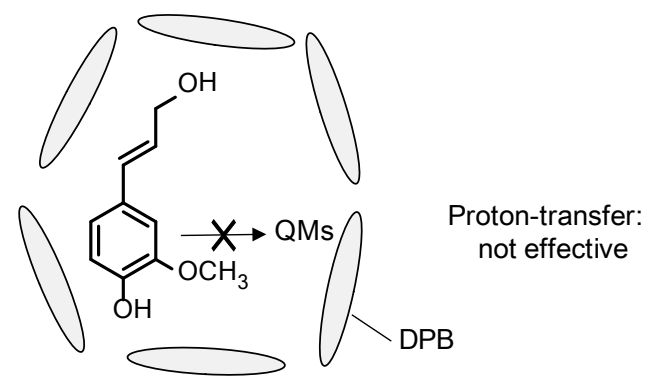

\section{B: Role of H-donor}

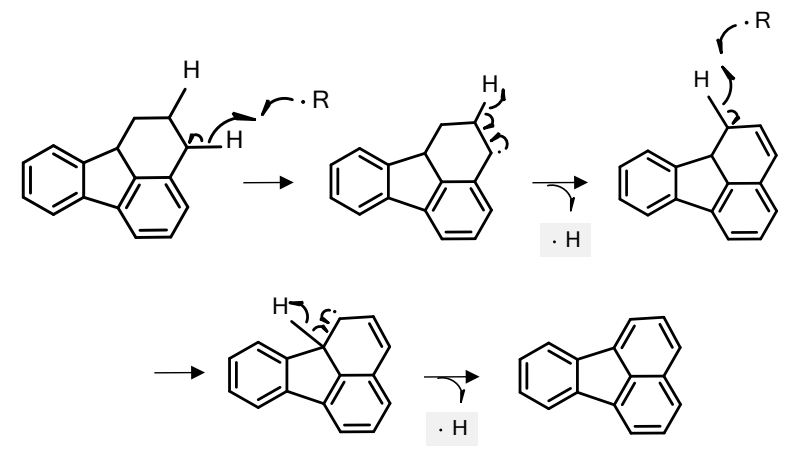

$\mathrm{H} \quad \Rightarrow$ Addition to $>\mathrm{C}=\mathrm{C}<\Rightarrow$ Dihydroconiferyl alcohol 
- Low temperature (such as $250^{\circ} \mathrm{C} \cdot \mathrm{H}$-deficient)

$\beta$-ether cleavage

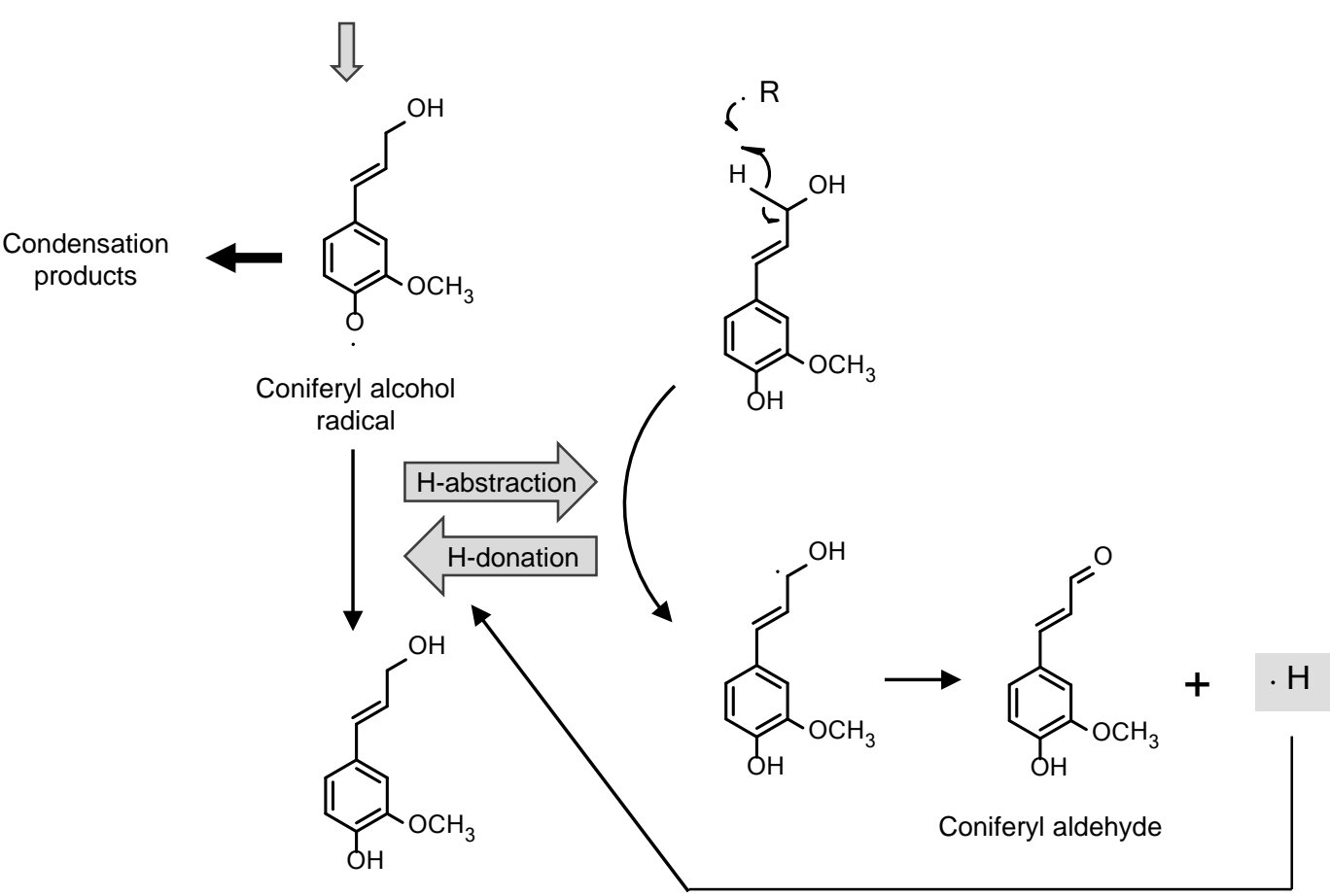

- High temperature (such as $350^{\circ} \mathrm{C}$ )

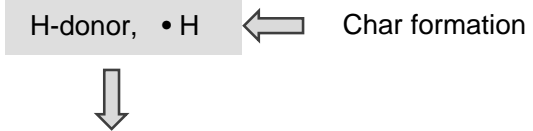

Stabilization of radicals

Side-chain reduction

Dihydroconiferyl alcohol and isoeugenol formation

Fig. 5 


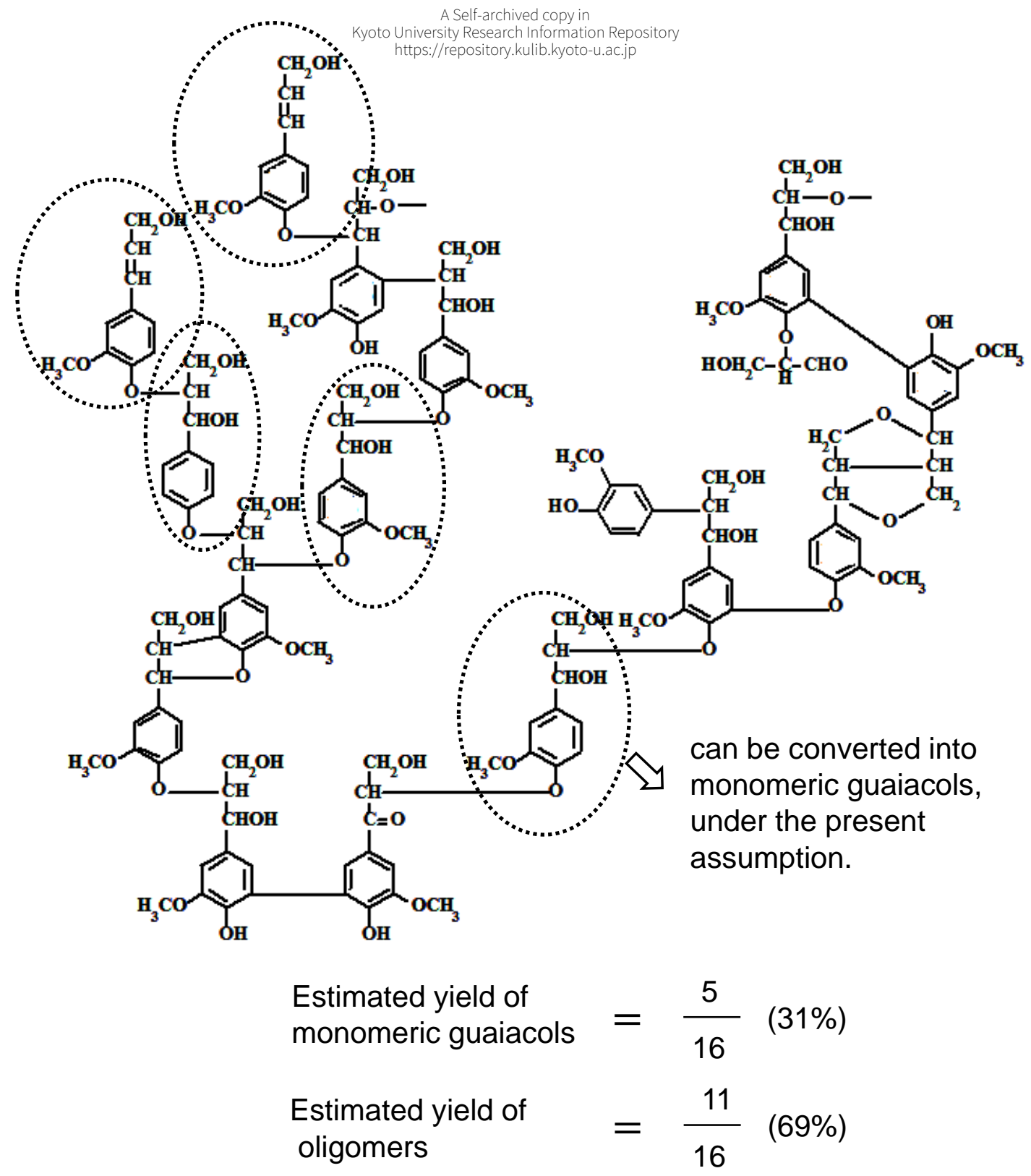




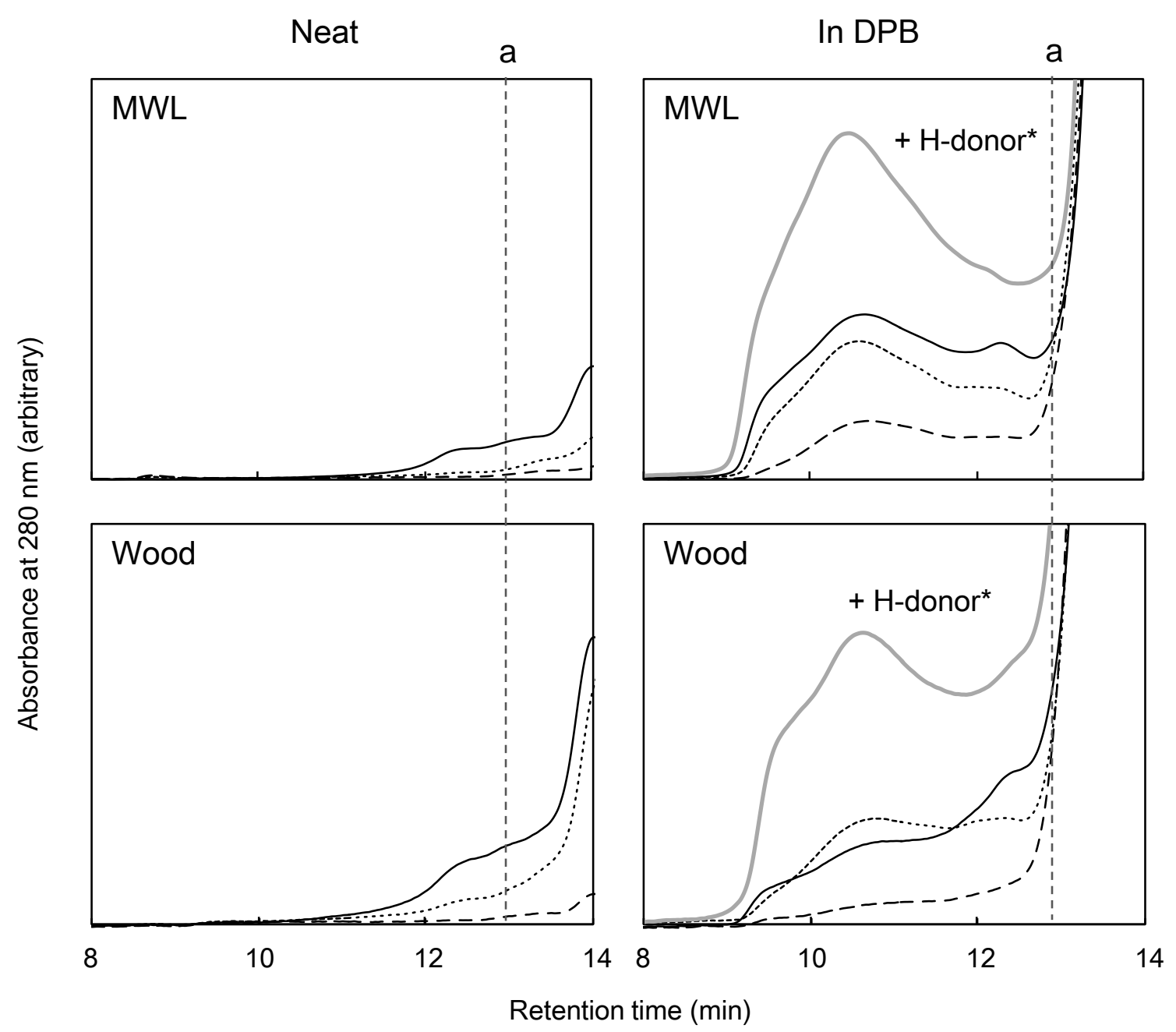

Fig. 7 


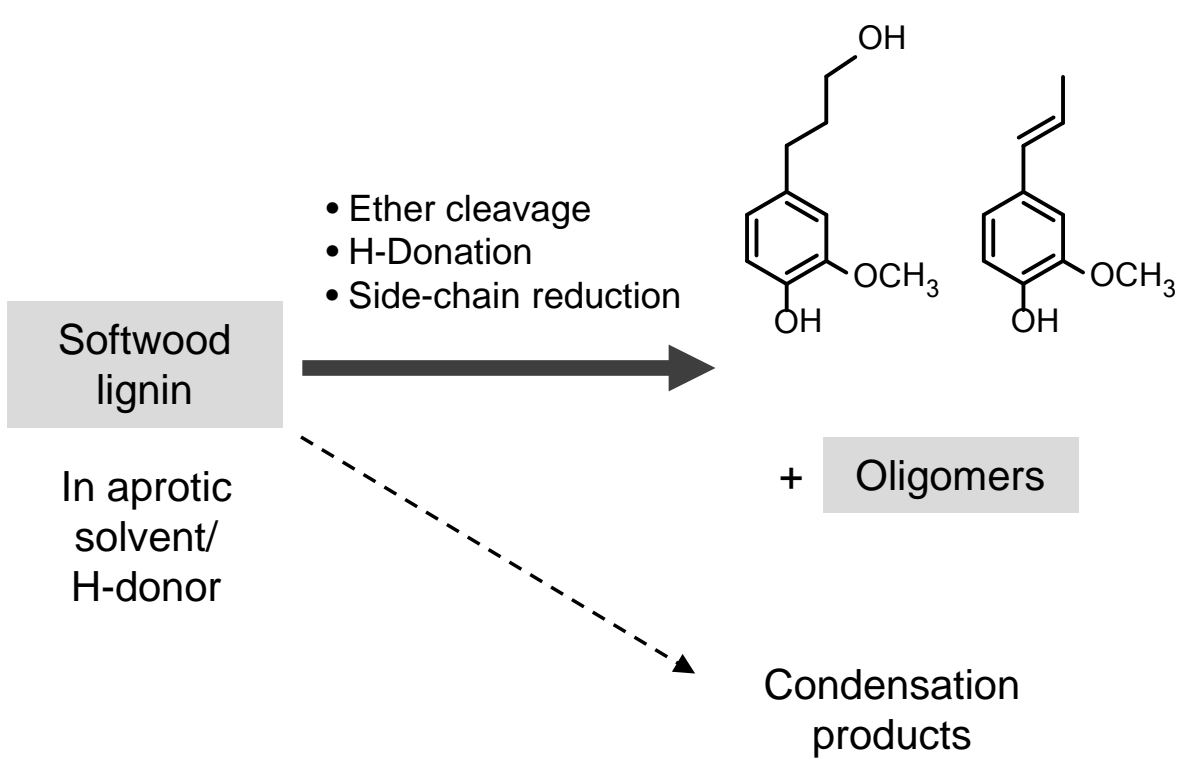

Fig. 8 